\title{
The Role of Paternal Drinking Problems in $\quad$ Original The Role of Paternal Drinking Problems in $\mid$ Article the Psychological Characteristics of High School Students
}

\author{
Dong Hyun Choi, Jong Sung Kim*, Jin Gyu Jung, Young Il Ryou, \\ Young Seok Kim, Won Chul Uh ${ }^{1}$
}

Department of Family Medicine, Research Institute for Medical Sciences, Chungnam National University School of Medicine; ${ }^{1}$ Health Promotion Center, Daejeon St. Mary's Hospital, The Catholic University of Korea College of Medicine, Daejeon, Korea

Background: It has been reported that children with parental drinking problems are at increased risk of drinking problems or psychiatric diseases in adulthood. The present study was conducted to examine the psychiatric characteristics of high school students according to paternal drinking problems.

Methods: The subjects were 950 high school students (390 male and 560 female). The paternal drinking problems were assessed by using the Father-Short Michigan Alcoholism Screening Test. The Alcohol Use Disorders Identification Test, Beck's depression inventory, and Beck's anxiety inventory were used to evaluate the drinking behavior, depression, and anxiety of high school students.

Results: While male students with paternal drinking problems showed significantly increased risk of anxiety (odds ratio [OR], 2.21; 95\% confidence interval [CI], 1.05 to 4.63), female students with paternal drinking problems showed significantly increased risk of depression (OR, 1.84; 95\% CI, 1.24 to 2.74 ) according to the results of logistic regression analysis with adjustments for participants' age, whether they live together with parents, their religion, club activities, and smoking habits on the basis of students without paternal drinking problems.

Conclusion: The above results suggest that paternal drinking problems lead to unstable mentalities in both male and female students, and that a family physician should address the mental state of teenagers with paternal drinking problems during clinical encounters.

Keywords: Fathers; Students; Alcohol; Depression; Anxiety

\section{INTRODUCTION}

Received: August 30, 2010, Accepted: August 22, 2013

${ }^{*}$ Corresponding Author: Jong Sung Kim

Tel: +82-42-280-8172, Fax: +82-42-280-7879

E-mail: jskim@cnuh.co.kr

Korean Journal of Family Medicine

Copyright (C) 2013 The Korean Academy of Family Medicine

(a) This is an open-access article distributed under the terms of the Creative Commons Attribution Non-Commercial License (http://creativecommons.org/licenses/by-nc/3.0) which permits unrestricted noncommercial use, distribution, and reproduction in any medium, provided the original work is properly cited.

The prevalence of lifetime alcohol abuse disorder has been reported to be $13.3 \%$ in Korea. ${ }^{1)}$ However, it is expected that the real number of alcoholics is much higher than the reported number because Korean culture is tolerant of alcohol consumption and Korean society tends not to consider drinking problems to be a disorder. $^{2)}$

Drinking problems not only damage an individual's physical and mental health but also cause negative effects on their family 
and society. So, it is reasonable to recognize drinking problems as a family disease rather than the alcoholic's own disease. The emotional cohesion of families with alcohol dependent patients is considered to be much weaker than that of general families. It has been reported that, among families with an alcohol dependent patient, $53.7 \%$ show the disengaged type and $24.4 \%$ show the rigid type of family model because they are less adaptable to difficult challenges. ${ }^{3)}$ These figures may break the harmony of family and build up extreme patterns of behavior and could inevitably lead to family dysfunction. ${ }^{4}$

In particular, children of alcoholic parents have been well known to have similar symptoms and behavioral traits due to their common experiences. Kammeier ${ }^{5)}$ has reported that a decent number of children from alcoholic families are emotionally unstable because they don't go through as normal of a development process as their peers do. In addition, Werner ${ }^{6}$ has said that parental drinking problems have an effect on the character, communication skills, self-images, and self-control capabilities of their children. Hawkins et al. ${ }^{7)}$ have insisted that the most significant factors having an effect on an adolescent's drinking behavior are parent's drinking behavior and attitude to drinking, and the parent-child relationship. These results suggest that parental drinking behavior and attitude to drinking have an important role in establishing their children's values and standards toward drinking.

A student's high school years are the latter part of adolescence and even though they are close physically to adulthood, it is the period during which teenagers establish their identity. ${ }^{8)}$ This period is also a very significant time in which an individual may develop psychiatric and physical health behaviors that can continue into adulthood. Family-related factors, especially those related to parental behavior in relation to health, are not excluded from the most important factors which affect psychiatric and physical health behavior during adolescence. ${ }^{9)}$ Therefore, authors think that health care in adolescence needs to consider familyrelated factors. It could be very important and meaningful to analyze parents' health habits to determine if they have an effect on their children's health behavior.

It has been reported by many studies in Korea that parental alcohol consumption affects the drinking behavior of adolescents. Additionally, studies in Korea have found that parental alcohol consumption affects the mental health of their children. However, there are few studies that investigate the role of parental drinking in contributing to adolescent drinking behavior as well as the mental state of these adolescents. Only one study ${ }^{10)}$ which targeted 79 high school students has shown the role of paternal drinking in the drinking behavior of female students during adolescence in the field of family medicine in Korea. The present study was conducted to find out whether or not the presence of paternal drinking problems might have an effect on the drinking behavior and psychological characteristics of their high schoolaged male and female children. The current study focused only on paternal drinking problems rather than the drinking habits of both parents. The participant students' drinking behavior was evaluated using the standard definitions of binge and heavy drinking. In addition, their mental health state was assessed.

\section{METHODS}

\section{Study Subjects}

Nine hundred and seventy male and female students of an academic high school in the Chungnam province of Korea were targeted from May 2009 to June 2009. A total of 950 subjects (390 male and 560 female) were included in the present study. They agreed to enrollment in the study and filled out the questionnaires with informed consent.

\section{Data Collection}

All subjects filled out the questionnaires by themselves with an explanation by a Family Medicine resident when they had questions. Questionnaires included general characteristics like sex, age, school grade, religion, living together with parents or not, and smoking habits. For the information on drinking, drinking quantity per session and weekly drinking frequency were investigated and the Alcohol Use Disorders Identification Test (AUDIT) was used. ${ }^{11)}$

A standard drink was considered $14 \mathrm{~g}$ of alcohol according to the guidelines issued by the National Institute Alcohol Abuse and Alcoholism (NIAAA). ${ }^{12)}$ Heavy drinking and binge drinking among male students were defined as consumption of 14 drinks or more a week and a maximum drinking quantity exceeding 4 standard drinks at a single session; for female students, it was 7 drinks and 3 drinks, respectively. ${ }^{13)}$ The Father-Short Michigan Alcoholism Screening Test (F-SMAST) ${ }^{14)}$ was used to evaluate 
the paternal drinking problems. Depression and anxiety as a factor of psychological characteristics was assessed with the use of Beck's Depression Inventory (BDI) ${ }^{15)}$ and Beck's Anxiety Inventory (BAI). ${ }^{16)}$

\section{Questionnaires}

\section{1) Alcohol Use Disorders Identification Test}

AUDIT is a self-reporting questionnaire that the World Health Organization ${ }^{11)}$ developed as a screening test for alcohol use disorders and to make a classification of hazardous drinking in the case of a score of $\geq 8$ in adult males. It was first adapted in Korea and translated to Korean by Kim. ${ }^{17)}$ Knight et al. ${ }^{18)}$ proved its validity with the use of an receiver operating characteristic curve for the ages of 14 to 18 years of adolescence. In our study, the Korean version was used and a score of $\geq 4$ was taken to define hazardous drinking.

\section{2) Father-Short Michigan Alcoholism Screening Test}

F-SMAST was developed as a questionnaire with 13 questions by Crews and Sher, ${ }^{14)}$ being filled out by children to assess paternal drinking problems. It recognizes paternal drinking as positive for drinking problem with a score of $\geq 3$. The Korean version by Lee et al. ${ }^{19)}$ was used for the present study.

\section{3) Beck's Depression Inventory}

BDI developed by Beck et al. ${ }^{15)}$ in 1961 is a widely used instrument for measuring the severity of depression. It consists of 21-questions about the depression level of a subject. Each question has a set of at least 4 possible answer choices, ranging in intensity. A score of 0 to 3 is assigned for each answer and then the total score is used to determine the severity of depression state. The total score of 0 to 9 indicates no depression; 10 to 15 , mild depression; 16 to 23, moderate depression; and 24 to 63 , severe depression. The present study recognized the total score of $\geq 10$ as positive for depression.

\section{4) Beck's Anxiety Inventory}

BAI was invented by Beck et al. ${ }^{16)}$ as a tool to discover the stress level of a subject. It is a 21-question, self-reporting inventory, expressing the cognitive, psychological or somatic symptoms (or components) of anxiety. Each question has a set of 4 possible answer choices on a 0 to 3 scale, ranging in intensity. The total score is used to assess the severity of anxiety. A total score of 0 to 21 indicates normal; 22 to 26 , mild to moderate anxiety; 27 to 31 , severe anxiety; and 32 or more, extreme anxiety. The total score of $\geq 22$ was recognized as positive for anxiety in the present study.

\section{Statistics}

To compare the general characteristics between male and female high school students, an independent t-test and chisquare test were used. The t-test was used to compare the scores of the AUDIT, BDI, and BAI according to whether the students indicated having paternal drinking problems or not. The adjusted odds ratio of heavy drinking, binge drinking, hazardous drinking, anxiety, and depression for the students with paternal drinking problems was calculated using logistic regression analysis to compare students without paternal drinking problems after adjustments for having religion, participation in club activities, smoking, and living together with parents. The analyses were conducted with SPSS ver. 13.0 (SPSS Inc., Chicago, IL, USA). A $\mathrm{P}$-value of $<0.05$ was considered statistically significant.

\section{RESULTS}

\section{General Characteristics of the Study Subjects}

The frequency of smoking of the male students and the female students was $12.1 \%$ and $2.1 \%$, respectively and significantly different $(\mathrm{P}<0.001)$. Subjects who drank alcohol were $28.0 \%$ of the study population (390 males and 560 females) and there was a significant difference $(P=0.001)$ between 132 male students (33.8\%) and 134 female students (23.9\%). The mean score of the AUDIT $(\mathrm{P}<0.001)$, the mean drinking quantity per session $(\mathrm{P}<0.001)$ and weekly drinking amount $(\mathrm{P}$ $=0.011$ ) were significantly different between the male and the female students. However, there were no significant differences in age, school grade, living together with parents, participation in club activities, or score of BDI, BAI, and F-SMAST between the male and female students (Table 1). 
Table 1. Characteristics of the subjects

\begin{tabular}{|c|c|c|c|c|}
\hline \multicolumn{2}{|l|}{ Characteristic } & \multirow{2}{*}{$\begin{array}{c}\text { Males }(\mathrm{n}=390) \\
16.5 \pm 1.0\end{array}$} & \multirow{2}{*}{$\begin{array}{c}\text { Females }(\mathrm{n}=560) \\
16.5 \pm 1.0\end{array}$} & \multirow{2}{*}{$\begin{array}{c}\text { P-value } \\
0.659\end{array}$} \\
\hline Age (y) & & & & \\
\hline \multirow[t]{4}{*}{ School grade } & & & & 0.256 \\
\hline & 1st & $147(37.7)$ & $183(32.7)$ & \\
\hline & 2nd & $128(32.8)$ & $192(34.3)$ & \\
\hline & 3rd & $115(29.5)$ & $185(33.0)$ & \\
\hline \multirow[t]{6}{*}{ Religion } & & & & 0.119 \\
\hline & Buddism & $42(10.8)$ & $81(14.5)$ & \\
\hline & Christian & $150(38.5)$ & $199(35.5)$ & \\
\hline & Catholic & $52(13.3)$ & 97 (17.3) & \\
\hline & Others & $9(2.3)$ & $8(1.4)$ & \\
\hline & None & $137(14.4)$ & $175(18.4)$ & \\
\hline \multirow[t]{3}{*}{ Residency } & & & & 0.840 \\
\hline & With parents & 375 (96.2) & 537 (95.1) & \\
\hline & Without parents & $15(3.8)$ & $23(4.1)$ & \\
\hline \multirow[t]{3}{*}{ Smoking state } & & & & $<0.001$ \\
\hline & Nonsmokers & 343 (87.9) & 548 (97.9) & \\
\hline & Smokers & 47 (12.1) & $12(2.1)$ & \\
\hline \multirow[t]{3}{*}{ Club activity } & & & & 0.082 \\
\hline & Yes & $328(84.1)$ & $493(88.0)$ & \\
\hline & No & $62(15.9)$ & $67(12.0)$ & \\
\hline Depression score $^{\dagger}$ & & $9.1 \pm 10.1$ & $10.0 \pm 8.3$ & 0.168 \\
\hline Anxiety score ${ }^{\ddagger}$ & & $8.3 \pm 9.8$ & $9.3 \pm 9.7$ & 0.117 \\
\hline Score of father's drinking problems ${ }^{\S}$ & & $2.0 \pm 1.8$ & $1.9 \pm 1.6$ & 0.548 \\
\hline \multirow[t]{3}{*}{ Father's drinking problems } & & & & 0.371 \\
\hline & Positive & $104(26.7)$ & $135(24.1)$ & \\
\hline & Negative & $286(73.3)$ & 425 (75.9) & \\
\hline \multirow[t]{3}{*}{ Drinking } & & & & 0.001 \\
\hline & Yes & 132 (33.8) & $134(23.9)$ & \\
\hline & No & $258(66.2)$ & $426(76.1)$ & \\
\hline AUDIT score & & $2.3 \pm 4.0$ & $1.4 \pm 3.4$ & $<0.001$ \\
\hline Drinks per drinking day & & $3.2 \pm 2.1$ & $2.5 \pm 1.4$ & $<0.001$ \\
\hline Drinks per week & & $1.2 \pm 3.3$ & $0.7 \pm 3.2$ & 0.011 \\
\hline
\end{tabular}

Values are presented as mean \pm SD or number (\%).

*B By independent t-test, chi-square test. ${ }^{\dagger}$ By Beck's Depression Inventory. ${ }^{\ddagger}$ By Beck’s Anxiety Inventory. ${ }^{\S}$ By Father-short Michigan Alcoholism Screening Test (F-SMAST). "Alcohol Use Disorders Identification Test. 
2. Drinking Behavior, Depression, and Anxiety of High School Aged Children according to Paternal Drinking Problems

Male students with paternal drinking problems showed a significantly higher score in the AUDIT $(\mathrm{P}=0.020)$, BDI $(\mathrm{P}$ $=0.005)$, and BAI $(P=0.024)$ than the male students without paternal drinking problems. However, there were no significant differences in the drinking quantity per session or weekly drinking amount between these two groups. Female students with paternal drinking problems showed a significantly higher mean score for the AUDIT $(\mathrm{P}=0.008)$ and BDI $(\mathrm{P}<0.001)$ than the female students without paternal drinking problems. The quantity of drinking per session, weekly drinking amount, and the mean score of BAI between these two female groups were not significantly different (Table 2).

\section{Odds Ratio of Heavy Drinking, Binge Drinking, Hazardous Drinking, Depression, and Anxiety of High School-aged Children with Paternal \\ Drinking Problems}

Given the results by logistic regression analysis adjusted for living together with parents, religion, club activities, and smoking on the basis of students without paternal drinking problems, the risk of anxiety (OR, 2.21; 95\% CI, 1.05 to 4.63 ) was significantly higher in the male group with paternal drinking problems than in the male group without it. The risk of depression (OR, 1.42; 95\% CI, 0.89 to 2.27 ) was also higher in the male group with paternal drinking problems than in the male group without paternal drinking problems, although it was not significantly different. On the contrary, the female students with paternal drinking problems showed a significantly increased risk of depression (OR, 1.84; $95 \%$ CI, 1.24 to 2.74 ) compared to the female students without

Table 2. Drinking behaviors, depression and anxiety of the high school students according to the father's drinking problems

\begin{tabular}{|c|c|c|c|c|c|c|}
\hline \multirow{2}{*}{ Variable } & \multicolumn{2}{|c|}{ Males } & \multirow{2}{*}{ P-value* } & \multicolumn{2}{|c|}{ Females } & \multirow{2}{*}{ P-value* } \\
\hline & $\operatorname{Positive}^{\dagger}(\mathrm{n}=104)$ & Negative $^{\ddagger}(n=286)$ & & $\operatorname{Positive}^{\dagger}(\mathrm{n}=135)$ & Negative $^{\ddagger}(n=425)$ & \\
\hline Drinks per drinking day & $3.5 \pm 2.2$ & $3.1 \pm 2.1$ & 0.172 & $2.7 \pm 1.5$ & $2.5 \pm 1.3$ & 0.084 \\
\hline Drinks per week & $1.7 \pm 4.5$ & $1.1 \pm 2.7$ & 0.216 & $1.2 \pm 4.4$ & $0.5 \pm 2.6$ & 0.094 \\
\hline AUDIT score & $3.2 \pm 5.6$ & $1.9 \pm 3.2$ & 0.020 & $2.3 \pm 5.0$ & $1.1 \pm 2.6$ & 0.008 \\
\hline Depression score & $11.8 \pm 12.2$ & $8.0 \pm 9.0$ & 0.005 & $12.1 \pm 9.9$ & $9.2 \pm 7.7$ & $<0.001$ \\
\hline Anxiety score & $10.4 \pm 11.4$ & $7.6 \pm 9.1$ & 0.024 & $10.7 \pm 11.3$ & $8.9 \pm 9.1$ & 0.092 \\
\hline
\end{tabular}

Values are presented as mean $\pm \mathrm{SD}$.

*By independent t-test. ${ }^{\dagger}$ Students whose fathers have drinking problems. ${ }^{\ddagger}$ Students whose fathers do not have drinking problems.

Table 3. Gender differences of drinking behaviors, anxiety, and depression on the high school students whose fathers have drinking problems

\begin{tabular}{lcc}
\hline \multicolumn{1}{c}{ Variable } & \multicolumn{2}{c}{ Odds ratio* $(95 \% \text { confidence interval })^{\text {Fales }}$} \\
\cline { 2 - 3 } & Females \\
\hline Binge drinking $^{\dagger}$ & $0.89(0.47-1.68)$ & $1.54(0.91-2.62)$ \\
Heavy drinking $^{\ddagger}$ & $0.67(0.06-7.02)$ & $0.31(0.01-6.88)$ \\
Harmful and hazardous drinking $^{\S}$ & $1.11(0.60-2.06)$ & $1.56(0.88-2.77)$ \\
Depression $^{\|}$ & $1.42(0.89-2.27)$ & $1.84(1.24-2.74)$ \\
Anxiety $^{\dagger}$ & $2.21(1.05-4.63)$ & $1.73(0.95-3.14)$ \\
\hline
\end{tabular}

*Using students whose fathers do not have drinking problems as the reference with adjustment for age, the living with parents, religion, club activity, smoking state. ${ }^{\dagger}$ Consumption of more than 4 drinks in men, or more than 3 drinks in women per drinking day. ${ }^{\ddagger}$ Consumption of more than 14 drinks for male, or more than 7 drinks for female per week. ${ }^{\varsigma}$ Four point or more for male and female in Alcohol Use Disorder Identification Test. "Ten points or more in the Beck's Depression Inventory. "Twenty-two points or more in the Beck's Anxiety Inventory. 
paternal drinking problems. The risk for anxiety ( $\mathrm{OR}, 1.73$; 95\% CI, 0.95 to 3.14) was also higher in the female group with paternal drinking problems than in the female group without paternal drinking problems, but not significantly different. The risks of heavy drinking, binge drinking, or hazardous drinking (the AUDIT score of $\geq 4$ ) were not significantly different according to whether the students had paternal drinking problems or not in both the male and female students (Table 3 ).

\section{DISCUSSION}

The drinking frequency of the total subjects was $28.0 \%$ (male $33.8 \%$ and female $23.9 \%$ ). This result was similar to the $29.4 \%$ (male $34.0 \%$ and female $25.4 \%$ ) found in the results of Lee et $\mathrm{al}^{20}{ }^{20}$ It suggests that there should be greater concern for drinking issues related to youth as much as for youth smoking issues.

The mean quantities of drinking per session and weekly drinking amount were 3.2 drinks and 1.2 drinks, respectively in the male students; and 2.5 drinks and 0.7 drinks, respectively in the female students. These quantities did not correspond with the definitions for binge drinking and heavy drinking for both the male and female students. Since college students are generally recognized as adults in society, they have fewer restrictions on drinking from parental, school, and social rules and expectations. Therefore, college students are easily exposed to socially permissible drinking circumstances. However, high school students are not allowed to drink alcohol by law and social norm. Moreover, Korean high school students are overburdened due to preparation for the college entrance examination. They study not only in school, but after school at private educational institutes forcing them to arrive home late at night. Therefore, this result might reflect the limited opportunity for high school students to drink alcohol in comparison to the opportunities for college students to drink alcohol.

In the present study, paternal drinking problems did not affect the drinking behavior of the male and female students. These results correspond well with the results of the study by Cho et $\mathrm{al}^{21)}$ showing that parental drinking problems are not associated with the drinking habits of high school aged children. Our results also show a similarity to the study of Yang et al., ${ }^{10)}$ reporting that parental drinking is not related to the drinking of adolescent children in the middle school to high school age range. On the other hand, $\mathrm{Yeh}^{22)}$ reported that the risk of adolescent problem drinking is relatively 4 times higher in children from paternal drinking backgrounds. Zhang et al. ${ }^{23)}$ described that paternal drinking has a direct effect on the drinking of their children. Additionally, it has been also mentioned by Weinberg et al. ${ }^{24)}$ that parental drinking increases the risk of alcohol misuse and heavy drinking by their children. These results suggest a variety of factors affect the drinking of high school students. Ann et al. ${ }^{25)}$ have stated that drinking with peers is the most influential factor in adolescent drinking. Teenagers are known to be affected mostly by family in the early part of adolescence and mostly by their community in the latter part. ${ }^{10)}$ Therefore, in interpretation of our results, authors think that the drinking of high school students is affected by social influences like relationships between peers or the influence of senior students on junior students rather than by the drinking problems of parents. High school years are part of the latter stages of adolescence in which students have more contact with peer groups than with family members. In addition, different study population could be considered one of the causes of these inconsistencies in the results, given that our study targeted general students. Previous research targeted children whose alcoholic parents were hospitalized in a detoxification center or a psychiatric ward.

The current study found that male students with paternal drinking problems were associated with more severe anxiety. Female students with paternal drinking problems were associated with more severe depression. These findings suggest that paternal drinking problems might cause an unstable mental state in both male and the female students. This is similar with the result of the study by Moos and Billings, ${ }^{26)}$ reporting that there is a significant possibility that children with parental drinking problems will have emotional problems. MacPherson et al. ${ }^{27)}$ also stated that a parent's drinking problem is one of the factors that aggravates their children's anxiety.

In this study, the male students with paternal drinking problems showed an increased rate of depression while the female students with paternal drinking problems had an increased rate of anxiety when compared to each group without paternal drinking problems, even though these differences were statistically not significant. Although the difference in the traits of anxiety and depression between genders is not yet fully understood, it is 
possible that paternal drinking problems might cause an unstable mentality in both male and female high school students, if we consider that anxiety and depression are comprehensively a kind of a psychosocial symptom. Therefore, it is suggested that family physicians may need to assess the mental state of teenagers with paternal drinking problems during clinical encounters. In addition, our results also suggest that it is necessary to assess the drinking habits of parents of high school students with psychosocial symptoms in order to screen whether these students are the children of alcoholics or not.

The limitations of our study are as follows. First, all the subjects were from a high school in the Chungnam province and there was a gender imbalance in that there were 170 more female students than male students. Therefore, the findings may not represent all Korean high school students. A larger sample size may be needed in future studies. Second, the students' relationship with friends and drinking with peers was not considered in our study, even though these are major causes of adolescent alcohol consumption. Finally, parental socioeconomic status and the drinking habits of other family members besides the father were not investigated. These limitations highlight that continuous studies are needed to investigate the diversified individual, family, and social factors affecting alcohol consumption of high school students.

One of the main aims of the present study is to investigate how paternal drinking problems can affect the psychological characteristics of high school students. In conclusion, paternal drinking problems had a significant effect on increased anxiety levels of male students and increased depression levels of female students, leading to unstable mentalities in both male and female students.

\section{CONFLICT OF INTEREST}

No potential conflict of interest relevant to this article was reported.

\section{REFERENCES}

1. Korean Ministry of Health and Welfare. The epidemiological survey of mental disorders in Korea 2011 [Internet]. Seoul: Ministry of Health and Welfare; 2012 [cited 2012 Dec 11]. Available from: http://stat.mw.go.kr/front/statData/ publicationView.jsp? $\mathrm{menuId}=47 \& \mathrm{bbsSeq}=13 \&$ nttSeq $=1845$ $8 \&$ searchKey $=\&$ searchWord $=\&$ nPage $=1$.

2. Kim KI, Won HT, Chang HI, Kim HS. Public ideas about mental illness in the Seoul area (I). J Korean Med Ass 1974; 17:959-66.

3. Kim JS. A study on the family type of alcoholism patients using family adaptability and cohesion evaluation scales (FACES III) [master's thesis]. Daejeon: Chungnam National University; 1994.

4. Cho HS, Woo JI, So IY, Moon YS, Lee HR, Kim JS. Analysis of factors correlated with the family function of alcoholics and their family. J Korean Acad Fam Med 1994;15:1088-107.

5. Kammeier ML. Adolescents from families with and without alcohol problems. QJ Stud Alcohol 1971;32:364-72.

6. Werner EE. Resilient offspring of alcoholics: a longitudinal study from birth to age 18. J Stud Alcohol 1986;47:34-40.

7. Hawkins JD, Catalano RF, Miller JY. Risk and protective factors for alcohol and other drug problems in adolescence and early adulthood: implications for substance abuse prevention. Psychol Bull 1992;112:64-105.

8. Song CH. Adolescent health care. J Korean Acad Fam Med 2002;23:267-80.

9. Kim TU, Yang SN, Choi JH, Kim SR, Koh HJ. The relation of health-related behaviors and family function in adolescents. J Korean Acad Fam Med 2005;26:9-14.

10. Yang SN, Kim TY, Kim SR, Choi JH, Koh HJ. The relation between father's and adolescent's health behavior. J Korean Acad Fam Med 2005;26:211-7.

11. Saunders JB, Aasland OG, Babor TF, de la Fuente JR, Grant M. Development of the Alcohol Use Disorders Identification Test (AUDIT): WHO collaborative project on early detection of persons with harmful alcohol consumption--II. Addiction 1993;88:791-804.

12. National Institute on Alcohol Abuse and Alcoholism. A pocket guide for alcohol screening and brief intervention [Internet]. Rockville (MD): National Institute on Alcohol Abuse and Alcoholism; 2005 [cited 2009 Oct 14]. Available from: http:// pubs.niaaa.nih.gov/publications/practitioner/PocketGuide/ pocket.pdf. 
13. National Institute on Alcohol Abuse and Alcoholism. Helping patients who drink too much: a clinician's guide updated 2005 edition. Rockville (MD): National Institute on Alcohol Abuse and Alcoholism; 2005.

14. Crews TM, Sher KJ. Using adapted short MASTs for assessing parental alcoholism: reliability and validity. Alcohol Clin Exp Res 1992;16:576-84.

15. Beck AT, Ward CH, Mendelson M, Mock J, Erbaugh J. An inventory for measuring depression. Arch Gen Psychiatry 1961;4:561-71.

16. Beck AT, Epstein N, Brown G, Steer RA. An inventory for measuring clinical anxiety: psychometric properties. J Consult Clin Psychol 1988;56:893-7.

17. Kim JS. Understanding of recovery process of alcoholic patients. J Korean Acad Fam Med 1998;19;S304-12.

18. Knight JR, Sherritt L, Harris SK, Gates EC, Chang G. Validity of brief alcohol screening tests among adolescents: a comparison of the AUDIT, POSIT, CAGE, and CRAFFT. Alcohol Clin Exp Res 2003;27:67-73.

19. Lee DH, Jung JG, Kim JS. Different effects of fathers' drinking problems on drinking behaviors, depression, and anxiety among Korean university students by gender. J Korean Acad Fam Med 2007;28:902-8.

20. Lee YS, Lee HR, Kang YJ. Smoking, alcohol and other drug use in Korean adolescents. J Korean Acad Fam Med 1998;19: 43-57.

21. Cho WJ, Kwon IS, Kim GS, Seo KM. Relationship between problematic drinking behavior and the personalities of high school students. J Korean Community Nurs 2004;15:471-82.

22. Yeh MY. Factors associated with alcohol consumption, problem drinking, and related consequences among high school students in Taiwan. Psychiatry Clin Neurosci 2006;60:46-54.

23. Zhang L, Welte JW, Wieczorek WF. The influence of parental drinking and closeness on adolescent drinking.J Stud Alcohol 1999;60:245-51.

24. Weinberg NZ, Dielman TE, Mandell W, Shope JT. Parental drinking and gender factors in the prediction of early adolescent alcohol use. Int J Addict 1994;29:89-104.

25. Ann JS, Kim HK, Choi ES. Factors influencing the alcohol consumption behavior of adolescents. J Korean Community Nurs 2003;15:55-65.

26. Moos RH, Billings AG. Children of alcoholics during the recovery process: alcoholic and matched control families. Addict Behav 1982;7:155-63.

27. MacPherson PS, Stewart SH, McWilliams LA. Parental problem drinking and anxiety disorder symptoms in adult offspring: examining the mediating role of anxiety sensitivity components. Addict Behav 2001;26:917-34. 